\title{
Development and implementation of a senior care program for older hospitalized patients: Bridging the gap between research, education and clinical practice in an academic service partnership
}

\author{
J ita G Hoogerduijn ${ }^{1}$, Saskia Weldam², Robert J van Barneveld ${ }^{2}$, Marieke J Schuurmans ${ }^{1,3}$ \\ 1. Research Group Care for the Chronically III, Faculty of Health Care, University of Applied Sciences Utrecht, Utrecht, the \\ Netherlands. 2. Department of Heart and Lung Diseases, University Medical Center Utrecht, Utrecht, the Netherlands. \\ 3. Department of Rehabilitation, Nursing Science \& Sports, Utrecht University, Utrecht, the Netherlands
}

Correspondence: Jita G Hoogerduijn. Address: Research Group Care for the Chronically III, Faculty of Health Care, University of Applied Sciences Utrecht, Bolognalaan 1013584 CJ Utrecht, The Netherlands. Telephone: 31-88-481-5201. Email: Jita.Hoogerduijn@hu.nl.

Received: July 4, 2012

DOI : $10.5430 /$ jnep.v3n10p26
Accepted: August 29, $2012 \quad$ Online Published: March 18, 2013

URL: http://dx.doi.org/10.5430/jnep.v3n10p26

\section{Abstract}

Aim: To describe a best practice focused on improving hospital care for older patients.

Background: $30 \%-60 \%$ of older patients will develop functional decline following hospital admission, resulting in increased dependency. In our ageing world the need to prevent functional decline is a priority for health care professionals.

Methods: In an academic service partnership, in which participated a University Medical Center and a University of Applied Sciences, an evidence based program was developed: "Home Faster and Better" to prevent functional decline and to enhance safe care for older patients ( $\geq 70$ years). Students of the Bachelor in Nursing Program developed the program, supervised by a clinical nurse specialist and a nurse scientist.

Results: A three-step care program, the DEFENCE model, (risk assessment, comprehensive geriatric assessment and targeted interventions) was developed as a best practice.

Conclusion: The partnership enhanced the transition of research into clinical practice, optimized the use of existing resources and created an inspiring learning environment for nursing professionals and students.

\section{Key words}

Nursing care, Functional decline, Prevention, Hospitalized older patients

\section{I ntroduction}

Health care professionals from several wards of a university teaching hospital (i.e. cardiology, cardiac surgery and lung diseases) were alarmed by the increasing length of stay of older patients. Older patients showed more complications, such as delirium and falls, developed functional dependency and experienced delayed discharge. Because the older population is increasing, the need for interventions to prevent these complications has become a priority for health care professionals 
and management ${ }^{[1]}$. Studies have projected that there will be a significant jump in the world's elderly population by 2030 . In Western Europe $28 \%$ and in the USA $21 \%$ of the population will be 65 and older ${ }^{[2]}$. The growth of the older population will lead to an increased number of older patients admitted to the hospital.

Hospital admission can be a risk for older patients as 30\%-60\% of older patients experience functional decline as a result of hospitalization ${ }^{[3-10]}$. Also in a recent multicenter study in the Netherlands $35 \%$ of the patients 65 and older acutely admitted to the internal wards of a hospital showed functional decline ${ }^{[11]}$. Functional decline is a loss of independence in self-care activities or a deterioration in self-care skills. More specifically, functional decline is often defined as a decline in the basic activities of daily living (ADL) (e.g., bathing, dressing, transferring from bed to chair and using the toilet) or in the instrumental activities of daily living (IADL) (e.g., shopping, housekeeping, preparing meals, taking medications, handling finances and using public transportation $)^{[10]}$.

Functional decline resulting from hospitalization has been shown to be related to a prolonged length of hospital stay, increased mortality rate, nursing home admission, increased dependency, decreased autonomy and quality of life ${ }^{[12,13]}$. Functional decline is not strictly related to the medical problem that initially caused hospitalization. Different pathways of functional decline, which are related to individual characteristics of patients and the iatrogenic aspects of hospitalization, have been described in the literature ${ }^{[14-17]}$. Aging has been associated with physical, psychological and social changes that increase susceptibility to various stresses and changes that represent loss of reserve function ${ }^{[9]}$. The individual response to the ageing process, the development of geriatric conditions (e.g., decreased mobility and visual and hearing problems), the development of geriatric syndromes (e.g., delirium and incontinence) and multimorbidity are all factors that contribute to the development of functional decline ${ }^{[18]}$. Moreover, several studies have suggested associations between chronic diseases, such as coronary artery disease and congestive heart failure, and geriatric syndromes, such as delirium, falls, pressure ulcers and incontinence ${ }^{[19,20]}$. Furthermore, the effects of bed rest (e.g., immobility and pressure ulcers) and other hospital-related complications (e.g., malnutrition and infections) have been shown to be associated with functional decline ${ }^{[19-23]}$.

Despite the problems older patients face during hospitalization, hospital care is mainly focused on medical problems. Thus, the needs of older patients based on their geriatric conditions and syndromes, which are often complex, fall outside the traditional disease model ${ }^{[24]}$.

Not all older individuals respond equally to stress and illness, and not all older patients develop functional decline related to hospitalization. Identification of patients who are at risk for functional decline is the first step in effective and efficient hospital care for the older patients. This enables the separation of those patients who need more than regular care from those for whom regular hospital care will be sufficient. For those at risk, a comprehensive geriatric assessment (CGA), which is focused on geriatric conditions and geriatric syndromes, should be applied, and this should be followed by targeted interventions to prevent functional decline ${ }^{[25]}$.

\section{Aim}

This paper describes the development and implementation of an evidence-based, three-step tailored care program (Home, Faster and Better) for older hospitalized patients to prevent functional decline and complications during hospitalization and to decrease length of stay.

\section{Clinical setting and objective}

The care program Home Faster and Better was developed for patients $\geq 70$ years who were admitted to the cardiology, cardiac surgery or lung diseases ward of an academic teaching hospital. The present program was based on the three-step DEFENCE model (Develop strategies Enabling Frail Elderly New Complications to Evade) (see Figure 1). In this model the first step is to identify patients at risk for functional decline, followed by step two: a comprehensive geriatric 
assessment for those at risk and step three; targeted interventions. The program should be incorporated in the electronic patient file (EPF) in such a way that it is easy for health care professionals to follow the different steps.

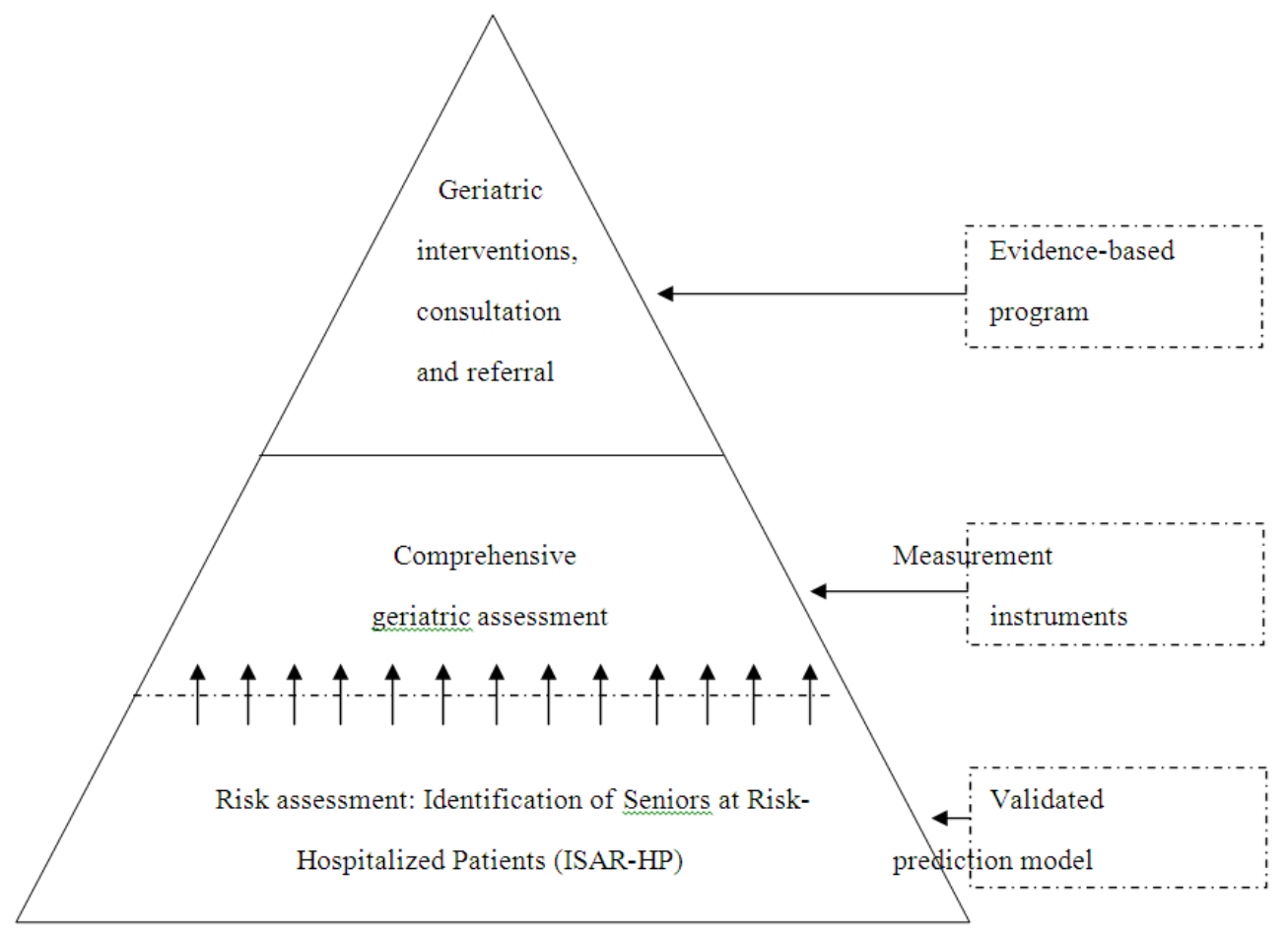

Figure 1. The DEFENCE model: Develop strategies Enabling Frail Elderly New Complications to Evade

Note. In the figure, the text should be in the boxes

\subsection{Organization}

An academic service partnership was realized with two participants: the University Medical Center, Division of Heart and Lungs and the University of Applied Sciences, Faculty of Health. Two project leaders were responsible for organizing the project: a clinical nurse specialist from the hospital who focused on integration and implementation, and a nurse scientist from the University of Applied Sciences who focused on the development of the content. Each step of the program was developed by a group of eight final-year bachelor students in nursing, and each group was supervised by the project leaders. During the process a nursing research panel, which consisted of nurses from the three wards, clinical nurse specialists and several experts commented on the different products of the students. A steering committee, which consisted of a nurse manager, a nursing policy advisor and a professor in geriatric nursing, was ultimately responsible for the results of the project. Managers of the wards advised the steering committee and approved the program.

\subsection{Development process}

The development process was equal for the two last steps of the program. For the first step, the identification of patients at risk for functional decline, we used the outcomes of a previous study. For the comprehensive geriatric assessment and the targeted interventions a literature study was conducted by the students. When available, also existing guidelines and protocols were also studied. Secondly, based on the literature, the content of the three steps was described and discussed within the student group and with the project leaders. This resulted in a draft that was discussed in the first Delphi round ${ }^{[26]}$ with the nursing research panel, and the draft was adjusted accordingly. The draft was then presented to the managers and clinical nurse specialists and experts from inside and outside the hospital for review. The revised version was discussed 
and adjusted in a second Delphi round with the nursing research panel, and its applicability was judged. After approval by the managers, the steering committee finally agreed on the different products.

\subsection{Incorporation in the electronic patient file}

The tailored care program was developed so that all steps could be incorporated in the EPF within the original patient file program. The electronic system automatically leads the professional through the steps. Starting with the inclusion of the targeted patient group (i.e., patients $\geq 70$ years), step one is the application of the screening instrument. A positive score automatically results in a comprehensive geriatric assessment to be filled in, the second step. Validated measurement tools with a threshold are automatically counted, and the threshold is applied. Finally, the program provides an overview of the geriatric conditions and syndromes for each patient, which is followed by targeted interventions. This third step involves describing and arranging these interventions into decision trees. A justification for all interventions is available for nurses to understand and defend the choices that are made. In addition, the program generates a standard discharge letter that lists the geriatric conditions and syndromes, and this is sent to the general practitioner.

\section{Results}

\subsection{Content of the care program}

Risk assessment: we used the Identification of Seniors at Risk - Hospitalized Patients (ISAR- HP) screening instrument to identify older patients at risk for functional decline ${ }^{[1,27]}$. This instrument has recently been developed and validated. The screening instrument exists of only four questions which makes it very easy to use in clinical practice (see Table 1).

Table 1. Scorecard: Identification of Seniors At Risk - Hospitalized Patients (ISAR-HP)

\begin{tabular}{lcc}
\hline Item & YES & NO \\
\hline $\begin{array}{l}\text { 1. Before hospital admission, did you need assistance for IADL (e.g., assistance in housekeeping, } \\
\text { preparing meals, shopping, etc.) on a regular basis? }\end{array}$ & 1 \\
2. Do you use a walking device (e.g., a cane, rollator, walking frame, crutches, etc.)? & 2 & 0 \\
3. Do you need assistance for traveling? & 1 & 0 \\
4. Did you continue education after age 14 ? & 0 & 1 \\
\hline Total score & \\
\hline Total score $0=$ not at risk & \\
Total score $\geq 2=$ patient at risk for functional decline & \\
\hline
\end{tabular}

Subsequently this prediction model was validated in older cardiac surgery patients $(n=475)$. Data collection was a part of the "Home Faster and Better" program, so the data for the validation in the cardiac surgery patients were partially collected by students who were supervised by a researcher.

Comprehensive geriatric assessment for patients at risk: a list of 11 geriatric conditions and syndromes (related with functional decline) was determined (i.e., polypharmacy, mobility, malnutrition, incontinence, fall risk, pressure ulcers, visual and hearing problems, cognition, pain and depression). Valid measurement tools were studied to diagnose the geriatric condition or syndrome or risk of the development of a geriatric condition or syndrome. When a validated measurement tool was not available, specific questions were applied (see Table 2).

Targeted Interventions: for each of the 11 geriatric conditions and syndromes, interventions were studied, determined, described and arranged in decision trees. The interventions ranged from referring the patient to other health care professionals, to educational, preventive and care interventions (see Table 2). Although nurses should pay attention to all 
described conditions and syndromes, not all geriatric problems should be treated in the hospital. For example, visual impairment should not be treated in the hospital in all cases, mostly patients are referred to an optometrist. In this example, staff members, nurses and other health care workers should be alerted to the increased risk of falling as a result of the visual impairment. In many cases, interventions involve a multidisciplinary team, and the nurse can bring up and coordinate these interventions.

Table 2. Elements of the Comprehensive Geriatric Assessment and Targeted Interventions

\begin{tabular}{|c|c|c|c|}
\hline Topic & Aim & Measurement & Interventions (short overview) \\
\hline Polypharmacy & $\begin{array}{l}\text { To promote medication } \\
\text { intake and adherence } \\
\text { and prevent } \\
\text { complications from } \\
\text { medications }\end{array}$ & $\begin{array}{l}\text { Do you use } \geq 5 \text { medications? } \\
\text { Did you use } \geq 3 \text { medications for more } \\
\text { than } 3 \text { months? } \\
\text { Were the medications prescribed by } \\
\text { different specialists? } \\
\text { Do you have problems with } \\
\text { medication intake? } \\
\text {-If yes, what is difficult for you? } \\
\text { Do you think the prescribed medicines } \\
\text { are improving your health situation? } \\
\text { Do you experience side effects from } \\
\text { the medications? } \\
\text {-Did this affect your medication } \\
\text { intake behavior? }\end{array}$ & $\begin{array}{l}\text { Make an overview of all medications } \\
\text { and prescriptions } \\
\text { Ask for "medications over the } \\
\text { counter" } \\
\text { Consult pharmacist and medical } \\
\text { doctor } \\
\text { Check and discuss adherence }\end{array}$ \\
\hline Mobility & $\begin{array}{l}\text { To maintain mobility as } \\
\text { much as possible }\end{array}$ & $\begin{array}{l}\text { Katz Index } 6 \text { questions: } \\
\text { Do you need assistance in bathing? } \\
\text { Do you need assistance in dressing? } \\
\text { Do you need assistance in using the } \\
\text { toilet? } \\
\text { Do you need assistance in } \\
\text { transferring? } \\
\text { Do you need assistance in eating? } \\
\text { Do you use incontinence materials? } \\
2 \text { additional questions: } \\
\text { Do you have problems in keeping } \\
\text { balance? } \\
\text { Do you experience problems with } \\
\text { mobility } \\
\text {-If yes, what kind of problems? } \\
\text {-If yes, use a fall-risk measurement } \\
\text { tool }\end{array}$ & $\begin{array}{l}\text { Start with discharge planning and } \\
\text { organize home care } \\
\text { Inform and educate patient and family } \\
\text { about the importance of mobilization } \\
\text { Promote and support self care } \\
\text { activities (e.g., bathing, dressing, } \\
\text { eating at the table, sitting in a chair } \\
\text { and walking around), which should be } \\
\text { supported by the family if possible } \\
\text { Mobilization scheme } \\
\text { Safe environment, be alert for risk of } \\
\text { falling } \\
\text { Consultation and referral to a } \\
\text { physiotherapist } \\
\text { Optimal day and night rhythm }\end{array}$ \\
\hline Malnutrition & $\begin{array}{l}\text { To identify malnutrition } \\
\text { and treat it properly }\end{array}$ & $\begin{array}{l}\text { MUST (malnutrition universal } \\
\text { screening tool): Quetelet index } \\
\text { Did you unintentionally lose weight in } \\
\text { the past } 6 \text { months? } \\
\text { Are you ill in a way that caused you } \\
\text { not to eat in the past } 5 \text { days, or is this a } \\
\text { possibility in the coming period? }\end{array}$ & $\begin{array}{l}\text { Inform medical doctor (reason for } \\
\text { malnutrition?) } \\
\text { Consult dietician } \\
\text { Control food and fluid intake } \\
\text { Follow protocol (e.g., eating at the } \\
\text { table, often small meals and snacks) } \\
\text { Be aware of the risk of pressure ulcers }\end{array}$ \\
\hline
\end{tabular}


Table 2. (continued.)

\begin{tabular}{|c|c|c|c|}
\hline Topic & Aim & Measurement & Interventions (short overview) \\
\hline Incontinence & $\begin{array}{l}\text { To be aware of } \\
\text { fall risk and risk } \\
\text { of bladder } \\
\text { infections }\end{array}$ & $\begin{array}{l}\text { Do you have problems with continence } \\
\text { (urination)? } \\
\text {-If yes, what kind of problems? } \\
\text { Do you unintentionally lose urine } \\
\text {-If yes, do you use incontinence materials? } \\
\text { Do you have to use the toilet during the night? } \\
\text {-If yes, use fall-risk measurement tool }\end{array}$ & $\begin{array}{l}\text { Is incontinence diagnosed, if not discuss } \\
\text { with medical doctor } \\
\text { Use the right incontinence materials } \\
\text { Be aware of the risk of pressure ulcers } \\
\text { Be aware of balanced fluid intake } \\
\text { Be aware of fall risk } \\
\text { Be aware of bladder infection and the } \\
\text { development of delirium }\end{array}$ \\
\hline Fall risk & $\begin{array}{l}\text { To be aware of } \\
\text { fall risk }\end{array}$ & $\begin{array}{l}\text { Did you have } \geq 1 \text { fall accident in the past } 6 \\
\text { months? } \\
\quad \text {-If yes use fall-risk measurement tool }\end{array}$ & $\begin{array}{l}\text { Inform patient and family } \\
\text { Alert all health care professionals in the EPF } \\
\text { Follow protocol to prevent falls (e.g., safe } \\
\text { environment and visual control) }\end{array}$ \\
\hline $\begin{array}{l}\text { Pressure } \\
\text { ulcers }\end{array}$ & & $\begin{array}{l}\text { Do you suffer a pressure ulcer, or do you have } \\
\text { a painful, red spot on your skin? } \\
\text { Are you bedridden? } \\
\text { Do you have mobility problems and suffer } \\
\text { incontinence? } \\
\quad \text {-If yes use PrePURSE score list }\end{array}$ & $\begin{array}{l}\text { Inform medical doctor } \\
\text { Apply skin inspection as prescribed } \\
\text { Follow protocol (e.g., appropriate mattress } \\
\text { and wound care materials) } \\
\text { Be aware of the right food and fluid intake } \\
\text { Consult nurse specialist } \\
\text { Consult dietician if necessary }\end{array}$ \\
\hline $\begin{array}{l}\text { Visual } \\
\text { problems }\end{array}$ & $\begin{array}{l}\text { To be aware of } \\
\text { fall risk and to } \\
\text { encourage } \\
\text { communication }\end{array}$ & $\begin{array}{l}\text { Do you use spectacles or lenses? } \\
\text { Do you see well (with spectacles or lenses)? }\end{array}$ & $\begin{array}{l}\text { Inform patient and family about the risk of } \\
\text { falling } \\
\text { Referral to an optometrist }\end{array}$ \\
\hline $\begin{array}{l}\text { Hearing } \\
\text { problems }\end{array}$ & $\begin{array}{l}\text { To encourage } \\
\text { communication } \\
\text { and promote } \\
\text { orientation }\end{array}$ & $\begin{array}{l}\text { Do you use a hearing aid: left/right? } \\
\text { Can you hear everything (with or without } \\
\text { hearing aid)? }\end{array}$ & $\begin{array}{l}\text { Alert all health care professionals in the EPF } \\
\text { Be aware of the right use of audio-aids } \\
\text { Referral to diagnose and receive the right } \\
\text { audio-aids }\end{array}$ \\
\hline $\begin{array}{l}\text { Cognitive } \\
\text { problems }\end{array}$ & $\begin{array}{l}\text { To pay attention } \\
\text { to the risk of } \\
\text { delirium or } \\
\text { dementia, use of } \\
\text { the Delirium } \\
\text { Observation } \\
\text { Scale }\end{array}$ & $\begin{array}{l}\text { Do you have memory problems? } \\
\text { Did you need help in ADL in the past } 24 \\
\text { hours? } \\
\text { Did you experience periods of confusion } \\
\text { during hospital admission or during illness? }\end{array}$ & $\begin{array}{l}\text { Risk of delirium: Three days DOS scale } \\
\text { If DOS is positive, follow protocol (e.g., } \\
\text { inform patient and family, safe and quiet } \\
\text { environment, adequate day and night } \\
\text { rhythm) } \\
\text { Consult geriatrician or psychiatrist } \\
\text { Dementia diagnosed? } \\
\text { Risk of dementia: consultation of a } \\
\text { geriatrician }\end{array}$ \\
\hline Pain & $\begin{array}{l}\text { To be aware of } \\
\text { pain and treat it } \\
\text { accordingly }\end{array}$ & $\begin{array}{l}\text { Do you have pain? } \\
\text {-If yes, use Visual Analogue Scale to } \\
\text { measure pain }\end{array}$ & $\begin{array}{l}\text { Consult medical doctor } \\
\text { Control, observe and evaluate the } \\
\text { medication }\end{array}$ \\
\hline Depression & $\begin{array}{l}\text { To be aware and } \\
\text { start adequate } \\
\text { diagnostics and } \\
\text { treatment, or } \\
\text { referral to } \\
\text { psychiatrist, as } \\
\text { needed }\end{array}$ & $\begin{array}{l}\text { Geriatric Depression Scale } 2 \text { questions: } \\
\text {-Did you experience feelings of depression, } \\
\text { or a melancholy mood last month? } \\
\text {-Did you feel less positive in daily } \\
\text { activities? } \\
\text {-If yes, use Hospital Anxiety and } \\
\text { depression (HADS) scale }\end{array}$ & $\begin{array}{l}\text { Positive HADS: consult geriatrician or } \\
\text { psychiatrist } \\
\text { Inform patient and family }\end{array}$ \\
\hline
\end{tabular}

Discharge planning was also an important part of the program. After analysis of the situation on the wards, two points of action were identified. First, we found that medical specialists and nurses should improve the communication with patients and their caregivers. Discharge planning starts the day the patient enters the hospital, and patients and their caregivers 
should be informed about the discharge procedure as soon as possible. Secondly, we identified a need for improved continuity of care. At discharge, all patient problems and relevant data, such as medication intake, geriatric conditions and syndromes are described in a letter to the general practitioner.

\subsection{I mplementation}

Within one year, the program was implemented as planned in three wards (one at a time), and the managers and staff of the wards supported the implementation. Training the nurses was an important aspect of the implementation, and several training rounds were organized to give all nurses the chance to participate in the educational program. Three training videos were made and used in the educational program. The training activities focused on improving knowledge of geriatric care, prevention of complications and appropriate use of measurement instruments. Improving competencies to work with the EPF was also part of the program. One nurse specialist and one senior nurse in each ward were responsible for monitoring and supporting further implementation of the senior care program.

\subsection{Evaluation and adjustment}

The implementation was evaluated after nine months. Several newly employed nurses were not sufficiently aware of the special needs of older patients. Moreover, working with the EPF was difficult for some of these nurses. A specific training program with lectures and clinical lessons was organized. For one week, eight nursing students were available everyday to help nurses use the EPF and the senior care program. As a result nurses are much more aware of the special needs of older patients and are more focused on these needs.

The content of the program was also updated to meet new regulations from the National Department of Health to promote safe care for older patients: starting 2012 the hospitals will have to register mobility, nutritional status, delirium and falls in older patients and the program we developed will be used to prevent negative outcomes on this topics. In addition, new outcomes from research studies were applied to the program.

The program was implemented in the whole academic hospital and it was the first step in an ongoing discussion focused on better health outcomes for older hospitalized patients in the whole hospital thus making an important contribution to this hospital outcome.

\section{Discussion}

Based on a need experienced in clinical nursing practice, a tailored care program, which followed the three-step DEFENCE model, was developed and implemented. The program was based on evidence found in the literature, clinical experiences and the advice of clinical nurse specialists and experts, and it was incorporated into the EPF. The application of the program in clinical practice was influenced by the knowledge of the specific needs of older patients and the competence to work with the EPF. A special training program was developed for the staff and repeated after nine months. Participation of the staff in the development, education, support of the clinical leaders and managers were the basic elements of effective implementation. In the development, the focus was on the use of validated measurement instruments and evidence-based interventions.

The first step in this program was to identify older patients at risk for functional decline based on the use of a screening instrument. In clinical practice, however, it is very difficult to predict outcomes when there are so many associated variables (e.g., the case of older patients). Functional decline is a complex phenomenon, and it cannot be predicted in $100 \%$ of patients. A screening instrument is a tool to help clinicians make the right decisions, and it should be used in combination with experienced clinical observations and a professional understanding of the problems of older patients.

With regard to interventions described for geriatric conditions and syndromes; in many cases these are not studied in patients admitted to regular clinical wards of a general hospital where the medical reason for admission is not specifically 
the geriatric problem. In other cases, there may simply be a lack of evidence of a specific intervention. For example, the problems of bed rest and immobility have been described in several studies ${ }^{[14,28,29]}$, but an evidence-based intervention to mobilize patients has not been described ${ }^{[30]}$. Therefore, the present program also utilized the experiences of nurses and the advice of clinical nurse specialists and experts. This program was tailored to the needs of both the patients and the hospital wards involved in the development process. The steps described in the program, however, are also applicable in other hospitals and hospital settings.

The development of content was mostly done by students. This was an exciting way for them to learn and improve their abilities to use research in clinical practice. In addition, they gained experience in writing reports, teamwork, cooperation and insight into the implementation process. Students were inspired by this program and their opinion towards working with older patients changed positively. This academic service partnership demonstrated a high level of innovation and optimized existing resources to incorporate research into clinical practice. In addition, it created an inspiring environment for both students and staff nurses.

\section{Conclusion}

We developed a tailored care program "Home Faster and Better" for patients $\geq 70$ years, which was based on the three-step DEFENCE model, to provide safe and effective care to older hospitalized patients, to prevent functional decline and complications during hospitalization and decrease the length of stay. This program was implemented firstly in three wards of an academic teaching hospital (i.e., cardiology, cardiac surgery and lung diseases) and secondly in the whole hospital. The program will help nurses and other health care professionals to provide integrated care focused on the specific needs of older patients.

The academic partnership enhanced the transition of research into clinical practice, optimized the use of existing resources and created an inspiring learning environment for nursing professionals and students. This project bridges the gap between research, education and clinical practice.

\section{Funding}

The project was funded by the University Hospital and the University of Applied Sciences.

\section{References}

[1] USCensus BN. Facts for features. 2010; CB10-FF.06.

[2] Kinsella K, He W. An Aging World: 2008, international population reports. 2009 06; International Population Reports, P95/09-1.

[3] Boyd CM, Xue QL, Guralnik JM, Fried LP. Hospitalization and development of dependence in activities of daily living in a cohort of disabled older women: the Women's Health and Aging Study I. J Gerontol A Biol Sci Med Sci. 2005 07; 60(7): 888-893.

[4] Covinsky KE, Palmer RM, Fortinsky RH, Counsell SR, Stewart AL, Kresevic D, et al. Loss of independence in activities of daily living in older adults hospitalized with medical illnesses: increased vulnerability with age. J Am Geriatr Soc. 2003; 51(4): 451-458.

[5] Gill TM, Allore HG, Holford TR, Guo Z. Hospitalization, restricted activity, and the development of disability among older persons. JAMA. 2004 11/03; 292(17): 2115-2124.

[6] Gill TM, Allore HG, Gahbauer EA, Murphy TE. Change in disability after hospitalization or restricted activity in older persons. JAMA. 2010 11/03; 304(17): 1919-1928.

[7] Sager MA, Franke T, Inouye SK, Landefeld CS, Morgan TM, Rudberg MA, et al. Functional outcomes of acute medical illness and hospitalization in older persons. Arch Intern Med. 1996 03/25; 156(6): 645-652.

[8] Sager MA, Rudberg MA. Functional decline associated with hospitalization for acute illness. Clin Geriatr Med. 1998; 14(4): 669-679.

[9] Creditor MC. Hazards of hospitalization of the elderly. Ann Intern Med. 1993 02/01; 118(3): 219-223.

[10] Hoogerduijn JG, Schuurmans MJ, Duijnstee MS, de Rooij SE, Grypdonck MF. A systematic review of predictors and screening instruments to identify older hospitalized patients at risk for functional decline. J Clin Nurs. 2007 01; 16(1): 46-57. 
[11] Hoogerduijn JG, Buurman BM, Korevaar JC, Grobbee DE, de Rooij SE, Schuurmans MJ. The prediction of functional decline in older hospitalised patients. Age Ageing. 2012 Feb 28. PMid:22378613 http://dx.doi.org/10.1093/ageing/afs015

[12] Covinsky KE, Justice AC, Rosenthal GE, Palmer RM, Landefeld CS. Measuring prognosis and case mix in hospitalized elders. The importance of functional status. J Gen Intern Med. 1997 04; 12(4): 203-208.

[13] Rudberg MA, Sager MA, Zhang J. Risk factors for nursing home use after hospitalization for medical illness. J Gerontol A Biol Sci Med Sci. 1996 09; 51(5): M189-M194.

[14] Inouye SK, Studenski S, Tinetti ME, Kuchel GA. Geriatric syndromes: clinical, research, and policy implications of a core geriatric concept. J Am Geriatr Soc. 2007 05; 55(5): 780-791.

[15] Hebert R. Functional decline in old age. CMAJ. 1997 10/15; 157(8): 1037-1045.

[16] Hoenig HM, Rubenstein LZ. Hospital-associated deconditioning and dysfunction. J Am Geriatr Soc. 1991 02; 39(2): $220-222$.

[17] Hirsch CH, Sommers L, Olsen A, Mullen L, Winograd CH. The natural history of functional morbidity in hospitalized older patients. J Am Geriatr Soc. 1990 12; 38(12): 1296-1303.

[18] Buurman BM, Hoogerduijn JG, de Haan RJ, Abu-Hanna A, Lagaay AM, Verhaar HJ, et al. Geriatric conditions in acutely hospitalized older patients: prevalence and one-year survival and functional decline. PLoS One. 2011; 6(11): e26951. PMid:22110598 http://dx.doi.org/10.1371/journal.pone.0026951

[19] Cigolle CT, Langa KM, Kabeto MU, Tian Z, Blaum CS. Geriatric conditions and disability: the Health and Retirement Study. Ann Intern Med. 2007 08/07; 147(3): 156-164.

[20] Lee PG, Cigolle C, Blaum C. The co-occurrence of chronic diseases and geriatric syndromes: the health and retirement study. J Am Geriatr Soc. 2009 03; 57(3): 511-516.

[21] Marengoni A, von SE, Rizzuto D, Winblad B, Fratiglioni L. The impact of chronic multimorbidity and disability on functional decline and survival in elderly persons. A community-based, longitudinal study. J Intern Med. 2009 02; 265(2): $288-295$.

[22] Wolff JL, Starfield B, Anderson G. Prevalence, expenditures, and complications of multiple chronic conditions in the elderly. Arch Intern Med. 2002 11/11; 162(20): 2269-2276.

[23] Wolff JL, Boult C, Boyd C, Anderson G. Newly reported chronic conditions and onset of functional dependency. J Am Geriatr Soc. 2005 05; 53(5): 851-855.

[24] Tinetti ME, Fried T. The end of the disease era. Am J Med. 2004 02/01; 116(3): 179-185.

[25] Ferrucci L, Guralnik JM, Studenski S, Fried LP, Cutler GB,Jr., Walston JD. Designing randomized, controlled trials aimed at preventing or delaying functional decline and disability in frail, older persons: a consensus report. J Am Geriatr Soc. 200404 ; 52(4): 625-634.

[26] Hasson F, Keeney S, McKenna H. Research guidelines for the Delphi survey technique. J Adv Nurs. 2000 Oct; 32 (4): $1008-1015$. PMid:11095242

[27] Hoogerduijn JG, Schuurmans MJ, Korevaar JC, Buurman BM, de Rooij SE. Identification of older hospitalised patients at risk for functional decline, a study to compare the predictive values of three screening instruments. J Clin Nurs. 2010 05; 19(9-10): 1219-1225.

[28] Brown CJ, Friedkin RJ, Inouye SK. Prevalence and outcomes of low mobility in hospitalized older patients. J Am Geriatr Soc 2004 08; 52(8): 1263-1270.

[29] Kortebein P, Symons TB, Ferrando A, Paddon-Jones D, Ronsen O, Protas E, et al. Functional impact of 10 days of bed rest in healthy older adults. J Gerontol A Biol Sci Med Sci. 2008 10; 63(10): 1076-1081.

[30] Brown CJ, Peel C, Bamman MM, Allman RM. Exercise program implementation proves not feasible during acute care hospitalization. J Rehabil Res Dev. 2006 11; 43(7): 939-946. 